\title{
The Importance of Bringing the Family Together. Exploring the Experience and Meaning of Family Health Conversations in Dementia Care
}

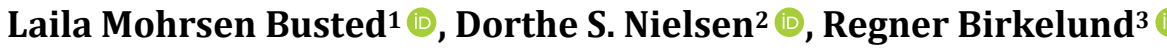 \\ ${ }^{1}$ The Department of Regional Health Research, Faculty of Health Sciences, University of Southern Denmark, \\ Odense, Denmark \\ ${ }^{2}$ The Health Sciences Research Center, UCL University College, Odense, Denmark \\ ${ }^{3}$ Migrant Health Clinic, Odense University Hospital, Center for Global Health, University of Southern Denmark, Odense, \\ Denmark
}

Email:1mbu1@ucl.dk

How to cite this paper: Busted, L.M., Nielsen, D.S. and Birkelund, R. (2019) The Importance of Bringing the Family Together. Exploring the Experience and Meaning of Family Health Conversations in Dementia Care. Open Journal of Nursing, 9, 1153-1172. https://doi.org/10.4236/ojn.2019.911085

Received: September 26, 2019

Accepted: November 25, 2019

Published: November 28, 2019

Copyright $\odot 2019$ by author(s) and Scientific Research Publishing Inc. This work is licensed under the Creative Commons Attribution International License (CC BY 4.0).

http://creativecommons.org/licenses/by/4.0/

\section{(c) (i) Open Access}

\begin{abstract}
Aim: The aim of this study was to investigate family members' experience of engaging in the "Family Health Conversations" intervention. Methods: A qualitative study was conducted with 15 family members who engaged in the intervention. The study used semi-structured interviews and data were analysed using reflexive thematic analysis. Findings: Through analysis and interpretation of the data, three themes were identified: 1) Support for navigating in unknown waters; 2) Bringing peace and relief to the family; 3) Involving the relative with dementia in Family Health Conversations. Family Health Conversations showed were beneficial to the families of persons with dementia and of great importance to both individual family members and the family. Involving the person with dementia in the Family Health Conversations was not always beneficial for the family. Conclusion: Deciding when to involve the person with dementia in Family Health Conversations requires thorough knowledge of the family as well as the person with dementia, to avoid excluding them. The intervention supports retaining selfhood and autonomy for the person with dementia, even when the individual did not participate in the conversation.
\end{abstract}

\section{Keywords}

Family Health Conversations, Dementia Care, Family Members 


\section{Introduction}

Dementia not only affects the person with dementia, but also affects and changes the lives of family members who must watch their family member become ill. Family members must respond to the relative's needs as their dependency increases and their behaviour changes [1] [2]. Globally, about 50 million people were living with dementia in 2018, which means that 50 million families are living with dementia affecting their lives [3]. In Denmark only 38,000 persons are diagnosed with dementia, although international population studies estimate that 89,000 persons in Denmark actually have dementia [4]. Most persons with dementia receive assistance from their family members, often their spouse. The adult children, often adult daughters and daughters-in-law, are also likely to provide care for the person with dementia [5]. It requires a lot of cooperation and communication among family members to arrange and organize the support needed by the relative with dementia [6]. Family members of persons with dementia often want to be involved in the person's care, but because of the complex situation, which involves many conflicting feelings, dementia family caregivers risk profound negative outcomes that can affect their health and well-being [7]. In this study, family caregivers are defined as the family members close to the person with dementia.

\section{Background}

Providing care for a person with dementia is extremely stressful and has far reaching consequences [8]. A review summarizing physiological and functional changes associated with dementia caregiver stress concluded that family caregivers often experience stress, depression, anxiety, and poor quality of life as a result of their caregiving role. The review also asserted that it might be useful to start viewing dementia caregiving as a health hazard [9]. To reduce the consequences of providing care to a person with dementia, interventions that support family members and caregivers are needed.

Dementia is known to have a large impact on relations within and across the family [6]. Interactions among family members change and relatives often change their roles within the family. Clemmensen et al. (2016) identified how two archetypes of relatives developed throughout the progression of dementia. The changing roles and interactions within the family seemed to risk potential conflicts smouldering beneath the surface. Another study investigated family conflicts in families with dementia [10] and found that they were based on rivalry, financial support, or disagreement regarding care. Conflicts among family members were caused by different views of what was perceived to be in the best interest of the person with dementia. Similarly, Mitrani et al. (2006) found that problematic family interaction patterns significantly contributed to distress among family caregivers of people with dementia [11]. This argues for developing interventions aimed at supporting protective family patterns to help prevent or alleviate the distress that caregivers experience and the risk of conflicts among family members when caring for a relative with dementia. 
Extensive literature has reported on interventions to relieve family caregiver burden and depression and promote both physical and psychological health among family caregivers. Interventions that provide generic educational components and psychoeducation skills tend to increase caregivers' knowledge about dementia, but have a less significant impact on caregiver burden and distress [8] [12]. Other interventions are based on physical training, stress and mood management, mindfulness, and counselling and support groups [13] [14] [15]. The interventions show overall good levels of satisfaction; psychosocial interventions have shown positive effects on caregivers' burden and satisfaction [16]. However, these interventions primarily focus on the individual family caregiver and her relation to the person with dementia rather than on interactions among family members and the family as the unit of care.

Family Health Conversations (FamHC) were developed with inspiration from models such as the "Calgary Family Assessment Model," the "Calgary Family Intervention Model" [17], and the "Illness Beliefs Model" [18] operationalized from the Family Systems Nursing theory developed by Wright and Lehey (2013). FamHC is a therapeutic relationship and conversation among the patient, the family, and a nurse. The conversation is facilitated by a health care professional, with the intent to strengthen the health of families and to create new meanings and opportunities in relation to the health problems within the family [19].

Illness in the family affects all family members, each of whom may have different reactions to the illness [20]. Some family members are capable of giving important support, others are challenged and may create conflicts or experience burdens within the family. The FamHC program asserts that the family has a significant impact on the health and well-being of individual members and therefore illness needs to be treated as a family affair. In this program the family is the unit of care and nursing interventions work collaboratively within the family to focus on interactions, relations, and reciprocity.

FamHC has been investigated with different types of chronic illness, such as families of older people with stroke, heart failure, psychiatric diagnoses, and families with ill children [21] [22] [23] [24] [25]. However, studies are needed to produce empirical evidence of what FamHC means to the family participating in the intervention. The FamHC intervention has not been examined in the context of dementia care.

\section{Aim}

The aim of this study was to investigate family members' experience of engaging in FamHC and what the intervention meant to them as individuals and to the family.

\section{Method}

\subsection{The Family Health Conversation Intervention}

A central concept in Family Health Conversations (FamHC) is that the dementia consultant approaches the family as the unit of care, acknowledging that the en- 
tire family is affected when one has dementia. The intervention was conducted by six dementia consultants: three nurses, two nurse assistants, and one occupational therapist. They offered skilled assessments of the person with dementia and their families and caregivers, working with families from the point of diagnosis throughout the course of care, providing emotional and psychological support, information and practical advice on caretaking, plus guidance about accessing services from the municipality. The dementia consultants completed four days of formal training at the UCL University College over a period of two weeks in spring 2018. The formal training focussed on attitudes, theoretical knowledge, and practical skills and involved knowledge of Family Systems Nursing theory. In FamHC, the dementia consultant and the family jointly explore structural, developmental, and functional aspects of the family [17]. In the formal training, the participants learned by using a genogram and an ecomap, which are graphic representations of family relations and social networks. They also learned by asking circular questions, offering caregiver support, and normalizing emotional responses as examples of family nursing interventions that target the cognitive, affective, and behavioural domains of family functioning. In the formal training, the participants worked on their practical skills in family nursing conversations by engaging in role plays and active dialogues with each other.

The intention of the FamHC intervention was to create a context for change related to each family's identified problems and resources. Telling the family's illness story has previously been related to unburdening oneself. Narrating and listening to each other in the family is as a way for making sense of suffering and finding hope. The FamHC provided a framework to illuminate the family and dementia consultants' expectations regarding the conversations. The family was a self-defined group of two or more individuals who considered themselves as close family members. During the FamHC, all family members were invited to tell their own stories and to listen to each other's feelings and thoughts about how they were experiencing the current situation. The conversations focused on topics chosen by the family, with the dialogue and questions aimed to identify and make use of the resources available within and outside the family [17] [19]. In some cases the families had only one FamHC, in other cases the families had two FamHCs.

The FamHC intervention was implemented in dementia healthcare in a municipality in Denmark. Dementia consultants responsible for visiting and caring for dementia families received education and supervision in family systems nursing and FamHC.

To ensure that the implementation of the FamHCs was consistent and successful, the dementia consultants were supervised. They received supervision by reflecting on their administration of FamHC both with each other and with the researcher responsible for the implementation. They also received supervision while conducting the FamHC and by having the responsible researcher participating in the FamHC provide feedback. The FamHC took place in the home of 
the person with dementia or at the Healthcare Center. In this current study, each family had one or two Family Health Conversations with the possibility to ask for more FamHCs. To systematize the FamHC intervention, one of the researchers observed some of the FamHC during the implementation period.

\subsection{Design}

This investigation was a qualitative exploratory study using semi-structured interviews inspired by Kvale and Brinkmann [26]. Data were analysed using Braun et al.'s model for reflexive thematic analysis [27].

\subsection{Participants and Recruitment}

The study included seven families. Eight interviews were conducted with 15 family members ranging in age from 13 to 72 . A total of eight daughters, three sons, two sons-in-law, a granddaughter and a grandson participated in the study. The inclusion criteria were family members participating in FamHC within the last 1 - 2 months. All families participated in the intervention with the relative with dementia involved; some families had a second FamHC without the relative with dementia. Purposeful sampling was used to recruit the participants based on typical case sampling [28] where the participants could narrate about engaging in the intervention and what it meant to them both individually and to the family.The dementia consultants randomly asked families if they were interested in participating in this study. Family members who showed an interest were contacted by the first author (LB), a female experienced homecare nurse and $\mathrm{PhD}$ student contacted the participants to arrange the interview. All interviews were conducted by the first author, responsible for implementation of the intervention. The relative diagnosed with dementia in the seven families ranged in age from 62 to 92. A description of the participants is shown in Table 1.

Table 1. Description of the pariticipants.

\begin{tabular}{|c|c|c|c|}
\hline & $\begin{array}{l}\text { The person with } \\
\text { dementia (age) }\end{array}$ & $\begin{array}{l}\text { Numbers of Family } \\
\text { Health Conversations }\end{array}$ & Participants (age) \\
\hline Family 1 & Mother with Alzheimer's (73) & Two & $\begin{array}{l}\text { Daughter, } 44 \text { (individual interview) } \\
\text { Daughter, } 51 \text { (individual interview) }\end{array}$ \\
\hline Family 2 & Mother with Alzheimer's (92) & One & $\begin{array}{c}\text { Daugther } 66 \text { (joint interview) } \\
\text { Daughter (68) } \\
\text { Daughter (69) } \\
\text { Daughter (71) } \\
\text { Son-in-law (72) }\end{array}$ \\
\hline Family 3 & Father with Alzheimer’s (76) & Two & $\begin{array}{c}\text { Daughter, } 43 \text { (joint interview) } \\
\text { Son-in-law (47) } \\
\text { Granddaughter (14) } \\
\text { Grandson (13) }\end{array}$ \\
\hline Family 4 & Father with Alzheimer's (83) & One & Daughter (51) (individual interview) \\
\hline Family 5 & Father with Alzheimer’s (84) & Two & Son, 60 (individual interview) \\
\hline Family 6 & Mother with Alzheimer's (62) & Two & Son, 60 (individual interview) \\
\hline Family 7 & Father with Alzheimer’s (81) & One & Son, 54 (individual interview) \\
\hline
\end{tabular}




\subsection{Data Collection}

The data were collected in 2018 and 2019 through individual or joint interviews. Some family members requested that the interview be joint, and their requests were respected. The interviews lasted between 28 and 68 minutes and took place at the participants' homes, except one that was conducted by telephone because the participant lived abroad, and one that took place at the participants' workplace. All interviews were audio recorded and transcribed verbatim, including field notations of non-verbal expressions such as silence, laughter, and crying.

Broad, open-ended questions were used to encourage narration [26]. For example, the interviewer asked "Please, tell me about your experience of participating in FamHC," "Please, tell me about what it has meant to you as a person," and "Do you experience your relations in your family have changed since participating in FamHC; if so, please tell me how?" Supplementary questions were also asked, such as "Please, clarify what you mean?" and "Can you say more about that?"

\subsection{Data Analysis}

The interviews were analysed in six phases using qualitative reflexive thematic analysis as described by Braun and Clarke and further developed by Braun, Clarke, Terry and Hayfield [27] [29]. A reflexive thematic analysis includes both a semantic and a latent level. Semantic codes stay at the "surface" of the data, capturing explicit meaning close to the participants' language. Latent codes focus on a deeper, more implicit or conceptual level of meaning, sometimes abstracted from the explicit content of the data. The latent level was chosen for the current study to see beyond the obvious meaning.

First phase: The first phase involved getting familiarized with the data through transcribing, reading it thoroughly, and generating ideas of what was in the data and what was interesting about it.

Second phase: Phase two involved generating initial codes. The data were approached with an inductive orientation. A long list of initial codes from the data was produced; for example, "helping each other in everyday life," "getting knowledge as a family," "more hugging and showing emotions," and "coordination within the family."

Third phase: In this phase, themes were constructed using codes as building blocks. They were constructed from the previous initial codes used to categorize the data (e.g., "the togetherness within families," "increased competencies," "emotionally preparing," and "practical preparing."

Fourth phase: Reviewing themes; the entire dataset was reviewed at two levels to identify potential themes and rework them, validate the potential themes, or create new themes.

Fifth phase: Phase five involved defining and naming themes, another stage of review where the themes were checked against the whole dataset to ensure that the data related to a central organizing concept. This process involved going 
back to collated data extracts to conduct and write detailed analyses that identified the story told by the theme. A latent level of analysis allowed an in-depth and nuanced understanding of each theme, including exploring potential subthemes and connections among them.

Sixth phase: This involved writing up the story of family members' experience with engaging in FamHC and what it meant to them both individually and as a family. The findings were continuously discussed among the authors to ensure consistency. Themes and subthemes were revised to clarify their content and to develop a richer more nuanced reading of the data. Although described as a linear process, the analysis process involved a constant back and forth movement between the whole and the parts of the data.

\subsection{Ethical Considerations}

The participants were introduced to the study through both verbal and written information and all gave written consent to participate. In situations where the participants wanted to participate in the interview as a joint interview, this was respected, and the interviews were then conducted both individually and as joint interviews. All participants were assured that participation was voluntary and that they could withdraw from the study at any time without giving a reason. All participants were assured of anonymity and confidentiality [30]. The Danish Data Protection Agency approved the study in accordance with the Act on Processing of Personal Data No. 2015-57-0016. Ethical clearance was obtained from a Danish Regional committee on health research ethics (S-20162000-158) and approval was not required according to Danish law. The study was conducted in accordance with the Declaration of Helsinki.

\section{Findings}

The analysis identified three themes that illustrate experiences of engaging in the FamHC intervention, including what it meant to individual family members and what it meant to the family. 1) Supporting navigation in unknown waters. 2) Bringing peace and relief into the family. 3) Involving the relative with dementia in Family Health Conversations.

\subsection{Supporting Navigation in Unknown Waters}

\subsubsection{Being Family in a New Way}

For the participants in this study, the difficult part of being related to a person with dementia was that it was the first time they experienced dementia as a disease in their family. Therefore, the family did not know what to expect and what they could prepare for. They felt like they were in uncharted waters. Dementia caused changes in their relative's behaviour, and this required family members to change their relationships with their relative. Participants explained they had to find and learn new ways to spend time with their relative with dementia and with their other family members. By encouraging family members to talk with 
each other while meeting with the dementia consultant, the FamHC became significant to the families. The family members became aware of the need to be a family in a new way while experiencing and learning about dementia and the challenges the disease involved.

Participants expressed that it was difficult to spend time together as a family when the relative with dementia changed behaviour. A participant described how FamHC helped to prepare younger family members on how to handle grandchildren difficulties when spending time with their grandfather:

"It was nice that there was someone who knew more about the disease than I did, who could explain it to my children. They were told what was happening to their grandfather. The dementia consultant gave Michael, 13 years old, some tricks and tools on how to communicate with his grandfather in the best way, now that he has dementia. And how the children should tackle and react when grandfather asks the same questions again and again" (daughter, 43, family 3 ).

This showed that it was easier to spend time together when family members increased their competence for tackling the challenges associated with a family member's dementia.

The support of the facilitating dementia consultant was significant and of great importance to the families in providing knowledge about the course of dementia. Everyone in the family expressed that they understood the relative with dementia and felt better equipped to meet future challenges. A participant described:

"It is only positive that we get knowledge, so we aren't surprised or scared along the way. We are in uncharted waters ... we haven't tried it before - so the advice and guidance that we can receive as the disease progresses is only good. We get the same knowledge in the family. It helps us, so that we aren't surprised or scared along the way - but there will probably be new things that we need help with all the time" (son-in-law, 47, family 3).

To the participants, FamHC presented an opportunity to learn about dementia, its progress in general, and how it may develop in the specific situation with their relative. The families experienced the opportunity as a chance to prepare themselves emotionally for some of the challenges that could arise in the dementia process.

\subsubsection{Facing Unexpected Practical Challenges and Decisions Together}

Before dementia developed, the person with dementia could make his or her own decisions, but now the person was cognitively challenged, and family members had to take responsibility for making decisions. One participant stated: "... it is annoying when we have to remember everything for her ..." (daughter, 51, family 1).

To be responsible for the person with dementia's memory in both easy and complex situations was difficult for family members. Deciding who should pay the bills and do the grocery shopping might be comparatively easy but discussing the possibility of their relative moving to a smaller home could be very com- 
plex. It was difficult for the families to discuss and agree on these different situations. Taking over decisions and responsibility for the relative with dementia required cooperation within the family and conversations among family members, especially when decisions needed to be in the spirit of how the relative would have done it him or herself.

Participants expressed that FamHC made it possible to prepare themselves for the practical challenges of being together with the person with dementia. They all understood that there were many practical things to be coordinated, such as the household, taking care of economic issues, doctor visits, and so on. A participant described: "There were so many practical things that we had not expected when it all began" (son, 60, family 5). FamHC contributed by facilitating family conversations that provided some overview, clarity, and control over the practical challenges and decisions. Being on top of the practical issues was of great importance to the families because these issues needed to be taken care of before family members could understand what was actually happening to the person with dementia, voice the emotional challenges they experienced, and discuss and agree on how to arrange the conditions around the relative with dementia in the spirit of what he or she would have wanted.

One of the characteristics of FamHCs in this study was that all contact with the family members was family focussed, regardless of whether it was a conversation with a single family member or with the whole family. A participant who lived close to his father described one of the first meetings with the dementia consultant:

"She gave me a good piece of advice early on in the process, that to not be burdened by my father's dementia, because I was responsible for everything, I should go home and together with my brother consider which one of us should be minister of finance, caretaker etc. She used those words. We had to do this as a family or otherwise I would buckle under the pressure, if I handled everything alone. It was her advice that I spoke with my brother. This resulted in us being closer to each other" (son, 54, family 7).

Participants expressed that the process of dementia was difficult for them to handle if they were alone with all the responsibilities. FamHC provided an opportunity for the family to identify the tasks they needed to handle and helped them find a way to assist each other by sharing the responsibility. FamHC thus resulted in the caregiver burden being shared among all family members. When meeting challenges together as a family and understanding how they could support each other by sharing practical tasks as a family, the caregiver burden was experienced as being much smaller.

\subsection{Bringing Peace and Relief into the Family}

\subsubsection{Challenges to the Individual Family Member}

For some family members, FamHC helped them, through conversations with their family members, to achieve insight into what the dementia condition meant to their specific experience of the process. At the same time, they all 
gained an understanding that it was okay to say no and think of themselves in the process. A participant said: "We have become better at helping each other, and it is okay to say that it is not her as a person you can't stand anymore, but her disease" (daughter, 44, family 1). The participants reported they learned that it was okay to take a break from the person with dementia and to take care of oneself. Family members became more attentive to each other by listening to one another's perceptions and worries, including the person with dementia. Some felt this could partly bring peace and relief, but it could also cause worries and concerns for each other:

A son was telling about a greater attention to and acknowledgement of his father with dementia:

"I have understood that he, with his age and with dementia ... We can't change him. And now I can find peace in that. It is much easier to spend time with my father now. I don't feel like it's my duty to visit him. I only come when I feel like it now" (son, 54, family 7).

The quote conveys how, without realising it, spending time with the person with dementia could be experienced as a pressure and an obligation. It also shows how FamHC promoted an understanding of the person with dementia's experience of the dementia process, helping participants accept the situation as it was and bringing peace and relief to the family members, helping them take better care of themselves. Spending time together without duty was experienced as much easier, and the burden they had experienced decreased.

However, an older brother described how FamHC made him aware of his brothers' and sisters' experiences, which gave him new worries:

"The conversation was good, but I have different worries for my family now. To see your siblings being sad was difficult, especially as the older brother, I have always felt that I should protect them since they were little and take care of them" (son, 37, family 6).

FamHC, also resulted in family members becoming more conscious about each other's experiences, worries and wishes.

\subsubsection{Challenges to the Family}

The participants reported that it normally was difficult to speak about dementia with each other, but FamHC created a situation where it became natural. A participant described the experience of the conversation: "It's difficult to be honest when your mother is sitting there. So, it's nice that the dementia consultant is sitting there. We could not do it on our own" (daughter, 51 family 1). It could be difficult for family members to put into words what they wanted to say. The interviews showed that the presence of the dementia consultant in the FamHCs made a positive difference for all family members.

FamHC created a situation where everyone in the family felt they were listened to. A participant described the experience of the conversation:

"In the conversation, the dementia consultant asked us all in turns, what we thought was important to talk about ... You couldn't really hide anything, which 
I thought was really good. We've all individually cried with our spouse or partner about mother's dementia. But to sit together as a family, with our parents and siblings and repeat out loud what you have told yourself that was difficult. But those feelings were good to put out there" (son, 37, family 6).

The quote shows how asking specific questions and listening to the individual's narratives created the opportunity to speak together within the family and listen to each other's concerns. Understanding and insight into each other's experiences regarding how the dementia process could be handled was created through narration and listening, which family members experienced as relieving.

In creating a situation where everyone in the family felt listened to, family members could also listen to each other's different experiences. Differences in the perception of the dementia disease and process became clear to the family members. A participant described: "We are five siblings and there are many opinions about it, so it's difficult, both with regard to how we experience it and what we think we should do about it" (son, 60, family 5). Another participant described: "It was nice to talk about things together and find an agreement together. Everyone is informed about the same things. There were different perceptions about things and the situation, but we figured it out' (daughter, 68, family 2). These two quotes describe how family members can have different perceptions of what was right for the person with dementia, but through conversation with each other they found consensus. At the same time, the quotes show that FamHC made it clear for the family that the person with dementia and family members did not necessarily have the same needs, wishes, or perceptions of the situation.

\subsection{Involving the Relative with Dementia in Family Health Conversations}

The participants expressed different concerns about involving the person with dementia in the conversations. Some of the participants tried the conversations both with and without the relative with dementia and therefore had different experiences. Some families spoke about involving their relative with dementia, which might feel natural and be successful, but could also be experienced as negative and burdening, especially for the person with dementia.

\subsubsection{When Involvement Is Natural and Successful}

In some participating families it was natural that their relative with dementia was involved in FamHC, and members of the family were able to speak freely about their feelings and their experiences of having dementia in the family. They experienced it as positive and felt it was a relief to share thoughts, joy, and worries together with the person with dementia. A participant described that FamHC helped resolve some conflicts in the family that they had been stuck on: "The FamHC resulted in us becoming aware about what father's wishes actually were. It surprised me because I didn't know that it was so deeply rooted in him" (son, 54, family 7). This shows that FamHC created a situation where important 
feelings and desires could be verbalised by both the family member with dementia and the family.

\subsubsection{When Involvement Is Marked by Concerns}

In other families, involving the person with dementia in FamHC was experienced as negative and burdensome to the family. Participants expressed a need to reach an agreement on how the situation in the family could be handled in the best way. There were situations where involving the person with dementia in FamHC was tried without success. A participant described:

"We tried to have a conversation with dad, but he couldn't follow and quickly left the conversation. It was a shame to try to keep him there. He went out and made coffee came in again and asked us when we were leaving?" (son, 60, family 5).

The family therefore chose to end the conversation and made a new appointment with the dementia consultant that did not involve their father.

The participants wanted to protect the relative from being exposed and some felt that involving the relative with dementia was a risk. One son of a mother with dementia reported that he would rather have avoided involving the parent with dementia. He said:

"I am very much in doubt about how much she understood, it's a mystery to figure out. Her answers during the conversations were totally off-I don't think that she can remember it an hour afterwards (shaking his head and pausing, hiding that he was crying)" (son, 37, family 6).

This shows that family members worried about the conversation exposing the relative with dementia's insufficiency, rather than being helpful to the family. Another participant also described how the family felt that they left with more frustration than before the FamHC. When this happened, the family needed a new FamHC that did not involve the person with dementia, to allow them to process their experiences and acknowledge that the consequences of dementia were so apparent.

It also was difficult to successfully carry out FamHC when the person with dementia did not have insight into their disease. A participant expressed that her mother with dementia did not acknowledge her dementia disease and felt overruled by the family in the FamHC when they needed to coordinate how they could handle the mother's financial issues:

"She was involved in the conversation, but she has unrealistic perceptions about herself-she thinks that she can learn how to use a computer, pay bills and administer her online bank affairs on her own. It s difficult to correct her without her becoming angry, because that is what she really thinks" (daughter, 44, family 1 ).

When the relative with dementia lacked insight into their disease, or the cognitive challenges became too difficult, family conversation could become difficult as well. Family members' desire to avoid upsetting the relative with dementia could be a barrier to their speaking freely about the dementia disease and 
sharing responsibilities within the family.

\section{Discussion}

The findings clearly show that FamHCs were of great significance to both individual family members and to the family. The findings highlight that FamHC creates possibilities for families to share feelings, experiences, and burdens related to the relative with dementia. This is consistent with previous research on FamHC by Benzein et al. (2015), Persson et al. (2014), and Östlund et al. (2016). These studies described how family members' narrating, listening, and reconsidering interactions with each other during FamHCs lessened the family's suffering and facilitated healing that strengthened family cohesion [23] [31] [32].

Our study shows how FamHC provided opportunities for families to achieve clarity and control over practical challenges following a dementia diagnosis in a family member. Family cooperation became important when the relative with dementia could no longer make decisions, requiring family members to step in to help and take responsibility. FamHC can be a way to help the family navigate through uncharted waters. A possible explanation for this is found in Antonovsky's (1987) theoretical approach to a sense of coherence, which relates to better health and quality of life outcomes. A sense of coherence comprises three elements: comprehensibility, manageability, and meaningfulness [33].

Comprehensibility refers to a belief that things occur in an orderly and predictable way and a sense that one can understand life events [33]. Our study showed that when a family is confronted with dementia, comprehensibility can be gained through FamHC. Gathering specific knowledge about dementia and preparing emotionally as a family for the challenges that can arise during the dementia process appears to increase comprehensibility for the family.

Manageability is a belief that one has skills and abilities, support, and the necessary resources to take care of things; that things are manageable and within control [33]. Engaging in FamHC appears to increase manageability in families by increasing competence for tackling the challenges associated with the disease. Knowing how to react when the dementia condition becomes obvious makes it easier for family members to spend time with the person with dementia.

Meaningfulness is a belief that things in life are interesting and a source of satisfaction, and that there is good reason and purpose to care about what happens [33]. FamHC creates a situation for the family to listen to each other's different experiences. The understanding and insight gained through FamHC are relieving and appear to increase meaningfulness for the family. FamHC offered families a sense of coherence through togetherness and jointly finding a way to cope with the new situation in the family.

This study also showed that FamHC created a situation where the family could speak naturally about the dementia process and what it meant to them, bringing peace and relief to the family. These findings are consistent with other studies' findings that allowing family members the opportunity to talk with their 
relatives during FamHC was a positive experience [34]. Benzein et al. (2015) also found that the opportunity to narrate, listen, ask each other questions, and reflect on other family members' stories helped families to create a full picture of their situation [31]. Our findings suggest that FamHC promotes resilient functioning in families, which contributes to family members' wellbeing. Luthar and Cicchetti [35] defined resilience as a dynamic process wherein individuals show positive adjustment despite negative life circumstances that are known to be associated with adjustment difficulties. Walsh [36] found that drawing out and affirming family strengths in the midst of difficulties helps to build a sense of confidence within a family, and that sharing beliefs fosters family resilience. In caregivers of persons with dementia, resilience has been found to be inversely related to depression, anxiety, and perceived burden, and therefore positively related to health and wellbeing [37].

Another important finding was that involving the relative with dementia in the FamHC was not necessarily beneficial for the family, especially when the person with dementia lacked insight into their disease or the cognitive challenges became difficult. In previous studies investigating FamHC with other chronic illnesses [31] [38] [39] [40] [41] [42], the person with the disease participated in the conversations, but our study showed that this was not always beneficial. In their theoretical work of family systems nursing, Wright and Lehey (2009) described one of five critical attributes to the concept of family as: "the unit's caregiving functions consist of protection, nourishment and socializations of its members" ([17], page 54). This could justify FamHCs being held without involving the relative with dementia as a means to nourish the other family members, but also to protect the person with dementia from being exposed or hurt. Agerskov et al. [43] argued that family nursing provides a confidential room for family members who cannot express powerlessness and frustration when the whole family is together. In this light, FamHC may ethically be held without involving the person with dementia if it benefits family members' ability to cope with the situation.

Not involving the person with dementia in FamHC may be controversial in regard to the political and professional intention of always involving the person of interest. Patient involvement is of great international interest [44] [45]. Overall, respecting patients' autonomy and putting them in charge of making decisions about their care is considered an ethical requirement. However, in a dementia setting the notion of autonomy as "making your own choices" is not sufficient when persons with dementia are dependent on the care of others [46]. Mackenzie and Stoljar (2000) introduced a relational approach to autonomy [47] [48] that highlights the social context within which all individuals exist and acknowledges the emotional and embodied aspects of decision makers. A relational autonomy approach acknowledges the central role of others in decision making (e.g., family members' role in relation to a person with dementia who lacks insight regarding the disease), where an individual's interests are developed 
jointly with others. FamHCs that include only the family members are not disrespectful to persons with dementia; rather, they allow persons with dementia to retain their selfhood and autonomy.

The open participant format of the interviews was the primary strength of the study. One limitation was that we could not include all persons with dementia as study participants because of cognitive dysfunction and personality changes and could not include all family members as participants because some declined to participate. The adult children, children-in-law, and grandchildren who participated in the study provided important perspectives that support the relevance of this qualitative study. However, the perspective of persons with dementia or the perspective of a healthy spouse engaging in FamHC were not examined in the current study and should be included in future research.

To strengthen the credibility of the findings, the researcher who conducted the participant interviews did not participate in the FamHC sessions. The interviews were conducted as individual or joint interviews, depending on the family's preference. After participating in FamHC, family members assumed that the study interview was also family focused. This was an advantage to the study, since the interplay among family members gave valuable insight to the meaning of FamHC for both individual family members and the family.

The current study's qualitative design was a strength because it provided an opportunity to discover and document unanticipated outcomes, such as family members' concerns about involving the person with dementia in FamHC.

Another study strength was that the intervention was implemented as a part of the dementia consultant's every day work. The discussions that surfaced during FamHCs were evaluated based on a realistic execution of dementia care in an actual care setting characterized by normal daily business and many patients. This study's participants were engaged in FamHC one month prior to being asked to be interviewed for the study, so their participation in FamHCs was independent of the study itself.

\section{Conclusions}

Our study shows that FamHCs are beneficial to families suffering from the effects of dementia in a family member and are important to both the individual family member and the famil. FamHC provided peace and relief to the family by allowing them to speak naturally about the dementia disease and what it meant to them. It also provided an opportunity for the family to gain clarity and control over the practical challenges posed by dementia. FamHC helped the family to navigate inherent difficulties and offered them a sense of coherence by enhancing their ability to cope with the new family situation. FamHC promotes resilient functioning in families, which contributes to family members' wellbeing.

Involving the person with dementia in the FamHC was not always beneficial for family members or the person with dementia, suggesting that as dementia progresses, FamHC should support family members in the practical challenges 
in the spirit of what the person with dementia would have wanted, promoting selfhood and autonomy to the extent possible.

\section{Relevance to Clinical Practice}

Conducting FamHC with families of people with dementia obliges dementia consultants to embrace the belief that illness needs to be treated as a family affair. Conducting FamHC requires knowledge about both the family and the person with dementia to facilitate a conversation that provides the family with the support they need. Facilitating FamHC requires special skills gained through education, practise, and feedback.

Engaging in FamHC at the beginning of the dementia journey when the diagnosis is made could be advantageous. At this point persons with dementia can still contribute to the conversation about their wishes for the future, allowing FamHC to involve the person with dementia while simultaneously contributing to the family's well-being. Read et al. [49] found that persons with newly diagnosed dementia have many thoughts about and wishes for their future but find it difficult to communicate these to the family. In this situation, FamHC should involve the person with dementia. Deciding not to involve the relative with dementia in FamHC in specific situations requires thorough knowledge of the family and the relative with dementia to avoid indiscriminately excluding the person with dementia. When including the person with dementia in FamHC does not succeed, the family's need for another FamHC with each other must be prioritised to support them in processing their experiences and help them arrange to handle the practical challenges together in the spirit of what their relative would have wanted.

\section{Acknowledgements}

The authors wish to thank the participants who generously shared their experiences, in the hope that it will lead to a better understanding, care and support of persons with young onset dementia.

\section{Funding}

The Open Access Fund of University of Southern Denmark has funded the publication fee of this paper.

\section{Conflicts of Interest}

The authors declared no potential conflicts of interest with respect to the research, authorship and/or publication of this article.

\section{References}

[1] World Health Organization, Alzheimer's Disease International (2012) Dementia: A Public Health Priority. World Health Organization, 252 p. http://www.who.int/mental_health/publications/dementia_report_2012/en/ 
[2] Livingston, G., Sommerlad, A., Orgeta, V., Costafreda, S.G., Huntley, J., Ames, D., et al. (2017) Dementia Prevention, Intervention, and Care. The Lancet, 390, 2673-2734. http://www.ncbi.nlm.nih.gov/pubmed/28735855 https://doi.org/10.1016/S0140-6736(17)31363-6

[3] Patterson, C. (2018) World Alzheimer Report 2018-The State of the Art of Dementia Research: New Frontiers. Alzheimer's Disease International, 1-48.

https://www.alz.co.uk/news/world-alzheimer-report-2018-state-of-art-of-dementiaresearch-new-frontiers

[4] Danish Dementia Research Centre (2017) Dementia in Denmark. 3. http://www.videnscenterfordemens.dk http://uk.videnscenterfordemens.dk/dementia-in-denmark/

[5] Schulz, R. and Martire, L.M. (2004) Family Caregiving of Persons with Dementia: Prevalence, Health Effects, and Support Strategies. American Journal of Geriatric Psychiatry, 12, 240-249.

https://www.sciencedirect.com/science/article/pii/S1064748112617746 https://doi.org/10.1097/00019442-200405000-00002

[6] Busted, L.M., Nielsen, D. and Birkelund, R. (2019) The Experience of Being in the Family of a Person with Earlystage Dementia-A Qualitative Interview Study. European Journal for Person Centered Healthcare, 7, 145-154.

[7] Merrilees, J. (2016) The Impact of Dementia on Family Caregivers: What Is Research Teaching Us? Current Neurology and Neuroscience Reports, 16, 88.

http://link.springer.com/10.1007/s11910-016-0692-z https://doi.org/10.1007/s11910-016-0692-Z

[8] Tremont, G. (2011) Family Caregiving in Dementia. Medicine and Health, Rhode Island, 94, 36-38. http://www.ncbi.nlm.nih.gov/pubmed/21456372

[9] Fonareva, I. and Oken, B.S. (2014) Physiological and Functional Consequences of Caregiving for Relatives with Dementia. International Psychogeriatrics, 26, 725-747. https://doi.org/10.1017/S1041610214000039

[10] Peisah, C., Brodaty, H. and Quadrio, C. (2006) Family Conflict in Dementia: Prodigal Sons and Black Sheep. International Journal of Geriatric Psychiatry, 21, 485-492. https://doi.org/10.1002/gps.1501

[11] Mitrani, V.B., Lewis, J.E., Feaster, D.J., Czaja, S.J., Eisdorfer, C., Schulz, R., et al. (2006) The Role of Family Functioning in the Stress Process of Dementia Caregivers: A Structural Family Framework. Gerontologist, 46, 97-105.

http://www.ncbi.nlm.nih.gov/pubmed/16452289

https://doi.org/10.1093/geront/46.1.97

[12] Kishita, N., Hammond, L., Dietrich, C.M. and Mioshi, E. (2018) Which Interventions Work for Dementia Family Carers?: An Updated Systematic Review of Randomized Controlled Trials of Carer Interventions. International Psychogeriatrics, 30, 1679-1696.

https://www.cambridge.org/core/product/identifier/S1041610218000947/type/journ al_article https://doi.org/10.1017/S1041610218000947

[13] Abrahams, R., Liu, K.P.Y., Bissett, M., Fahey, P., Cheung, K.S.L., Bye, R., et al. (2018) Effectiveness of Interventions for Co-Residing Family Caregivers of People with Dementia: Systematic Review and Meta-Analysis. Australian Occupational Therapy Journal, 65, 208-224. http://www.ncbi.nlm.nih.gov/pubmed/29527683 https://doi.org/10.1111/1440-1630.12464

[14] Hurley, R.V.C., Patterson, T.G. and Cooley, S.J. (2014) Meditation-Based Interventions for Family Caregivers of People with Dementia: A Review of the Empirical Li- 
terature. Aging and Mental Health, 18, 281-288.

http://www.ncbi.nlm.nih.gov/pubmed/24093954

https://doi.org/10.1080/13607863.2013.837145

[15] Jensen, M., Agbata, I.N., Canavan, M. and McCarthy, G. (2015) Effectiveness of Educational Interventions for Informal Caregivers of Individuals with Dementia Residing in the Community: Systematic Review and Meta-Analysis of Randomised Controlled Trials. International Journal of Geriatric Psychiatry, 30, 130-143. https://doi.org/10.1002/gps.4208

[16] Qiu, D., Hu, M., Yu, Y., Tang, B. and Xiao, S. (2019) Acceptability of Psychosocial Interventions for Dementia Caregivers: A Systematic Review. BMC Psychiatry, 19, 23. http://www.ncbi.nlm.nih.gov/pubmed/30642300 https://doi.org/10.1186/s12888-018-1976-4

[17] Wright, L.M. and Leahey, M. (2013) Nurses and Families: A Guide to Family Assessment and Intervention. $351 \mathrm{p}$.

[18] Wright, L.M. and Bell, J.M. (2009) Beliefs and Illness: A Model for Healing. 4th Edition, Floor Press, Calgary, Canada, 385 pp.

[19] Benzein, E., Hagberg, M. and Saveman, B.-I. (2008) Being Appropriately Unusual: A Challenge for Nurses in Health-Promoting Conversations with Families. Nursing Inquiry, 15, 106-115. https://doi.org/10.1111/j.1440-1800.2008.00401.x

[20] Denham, S. (2015) Towards a Family-Focused Care. In: Denham, S., Eggenberger, S., Krumwiede, N. and Young, P., Eds., Family-Focused Nursing Care, F.A. Davis, Philadelphia, PA, 25-47.

[21] Gisladottir, M., Treasure, J. and Svavarsdottir, E.K. (2017) Effectiveness of Therapeutic Conversation Intervention among Caregivers of People with Eating Disorders: Quasi-Experimental Design. Journal of Clinical Nursing, 26, 735-750.

http://www.ncbi.nlm.nih.gov/pubmed/27239974 https://doi.org/10.1111/jocn.13412

[22] Lämås, K., Sundin, K., Jacobsson, C., Saveman, B.-I. and Östlund, U. (2016) Possibilities for Evaluating Cost-Effectiveness of Family System Nursing: An Example Based on Family Health Conversations with Families in which a Middle-Aged Family Member Had Suffered Stroke. Nordic Journal of Nursing Research, 36, 74-81. http://journals.sagepub.com/doi/10.1177/0107408315610076 https://doi.org/10.1177/0107408315610076

[23] Östlund, U., Bäckström, B., Saveman, B.I., Lindh, V. and Sundin, K. (2016) A Family Systems Nursing Approach for Families Following a Stroke: Family Health Conversations. Journal of Family Nursing, 22, 148-171.

http://journals.sagepub.com/doi/10.1177/1074840716642790 https://doi.org/10.1177/1074840716642790

[24] Voltelen, B., Konradsen, H. and Østergaard, B. (2016) Family Nursing Therapeutic Conversations in Heart Failure Outpatient Clinics in Denmark: Nurses' Experiences. Journal of Family Nursing, 22, 172-198.

http://journals.sagepub.com/doi/10.1177/1074840716643879 https://doi.org/10.1177/1074840716643879

[25] Wacharasin, C., Phaktoop, M. and Sananreangsak, S. (2015) Examining the Usefulness of a Family Empowerment Program Guided by the Illness Beliefs Model for Families Caring for a Child With Thalassemia. Journal of Family Nursing, 21, 295-321. http://journals.sagepub.com/doi/10.1177/1074840715585000 https://doi.org/10.1177/1074840715585000

[26] Kvale, S. and Brinkmann, S. (2015) Interview-Det kvalitative forskningsinterview 
som håndværk. 3rd Edition, Hans Reitzels Forlag, Copenhagen.

[27] Braun, V., Clarke, V., Hayfield, N. and Terry, G. (2018) Thematic Analysis. In: Liamputtong, P, Ed., Handbook of Research Methods in Health Social Sciences, Springer Singapore, Singapore, 843-860.

http://link.springer.com/10.1007/978-981-10-5251-4_103

https://doi.org/10.1007/978-981-10-5251-4_103

[28] Patton, M.Q. (2015) Qualitative Research \& Evaluation Methods: Integrating Theory and Practice. $806 \mathrm{p}$.

https://uk.sagepub.com/en-gb/eur/qualitative-research-evaluation-methods/book23 2962

[29] Braun, V. and Clarke, V. (2006) Using Thematic Analysis in Psychology. Qualitative Research in Psychology, 3, 77-101. https://doi.org/10.1191/1478088706qp063oa

[30] Richards, H. and Schwartz, L. (2002) Ethics of Qualitative Research: Are There Special Issues for Health Services Research? Family Practice, 19, 135-139.

https://doi.org/10.1093/fampra/19.2.135

[31] Benzein, E., Olin, C. and Persson, C. (2015) “You Put It All Together"-Families' Evaluation of Participating in Family Health Conversations. Scandinavian Journal of Caring Sciences, 29, 136-144. https://doi.org/10.1111/scs.12141

[32] Persson, C. and Benzein, E. (2014) Family Health Conversations: How Do They Support Health? Nursing Research and Practice, 2014, Article ID: 547160.

http://www.ncbi.nlm.nih.gov/pubmed/24800068 https://doi.org/10.1155/2014/547160

[33] Antonovsky, A. (1987) Unraveling the Mystery of Health: How People Manage Stress and Stay Well. Jossey-Bass, San Francisco, CA, 218 p.

[34] Hollman Frisman, G., Wåhlin, I., Orvelius, L. and Ågren, S. (2018) Health-Promoting Conversations-A Novel Approach to Families Experiencing Critical Illness in the ICU Environment. Journal of Clinical Nursing, 27, 631-639. http://www.ncbi.nlm.nih.gov/pubmed/28722814 https://doi.org/10.1111/jocn.13969

[35] Luthar, S. and Cicchetti, D. (2001) Development and Psychopathology. Development and Psychopathology, 12, 857-885.

https://www.cambridge.org/core/journals/development-and-psychopathology/articl e/construct-of-resilience-implications-for-interventions-and-social-policies/FB0F35 A81AD0C3332078FE8C13D403A0 https://doi.org/10.1017/S0954579400004156

[36] Walsh, F. (2002) A Family Resilience Framework: Innovative Practice Applications. Family Relations, 51, 130-137. https://doi.org/10.1111/j.1741-3729.2002.00130.x

[37] O'Rourke, N., Kupferschmidt, A.L., Claxton, A., Smith, J.Z., Chappell, N. and Beattie, B.L. (2010) Psychological Resilience Predicts Depressive Symptoms among Spouses of Persons with Alzheimer Disease over Time. Aging \& Mental Health, 14, 984-993. http://www.tandfonline.com/doi/abs/10.1080/13607863.2010.501063 https://doi.org/10.1080/13607863.2010.501063

[38] Dorell, Å. and Sundin, K. (2016) Becoming visible-Experiences from Families Participating in Family Health Conversations at Residential Homes for Older People. Geriatric Nursing, 37, 260-265. https://doi.org/10.1016/j.gerinurse.2016.02.015

[39] Faarup, I., Lauridsen, J.T., Lütgen, K., Nørregaard, A., Poulsen, F.R. and Østergaard, B. (2019) Do Family Health Conversations Impact Patients with Glioblastoma Multiforme and Their Family Members? Journal of Clinical Nursing, 28, 1695-1707. http://www.ncbi.nlm.nih.gov/pubmed/30653774 
https://doi.org/10.1111/jocn.14777

[40] Kamban, S.W. and Svavarsdottir, E.K. (2013) Does a Therapeutic Conversation Intervention in an Acute Paediatric Setting Make a Difference for Families of Children with Bronchiolitis Caused by Respiratory Syncytial Virus (RSV)? Journal of Clinical Nursing, 22, 2723-2733. https://doi.org/10.1111/j.1365-2702.2012.04330.x

[41] Voltelen, B., Konradsen, H. and Østergaard, B. (2018) Family Nursing Therapeutic Conversations: Family Reorganization Processes after Diagnosis. Family Relations, 67, 600-614. https://doi.org/10.1111/fare.12329

[42] Svavarsdottir, E.K. and Sigurdardottir, A.O. (2013) Benefits of a Brief Therapeutic Conversation Intervention for Families of Children and Adolescents in Active Cancer Treatment. Oncology Nursing Forum, 40, E346-E357.

http://www.ncbi.nlm.nih.gov/pubmed/23989027

https://doi.org/10.1188/13.ONF.E346-E357

[43] Agerskov, H., Dieperink, K.B. and Konradsen, H. (2019) At sætte patienten i centrum er ikke nok. Klinisk Sygepleje, 33, 166-170.

https://www.idunn.no/klinisk_sygepleje/2019/02/at_saette_patienten_i_centrum_er _ikke_nok

https://doi.org/10.18261/issn.1903-2285-2019-02-07

[44] Regioner, D. (2019) Patientinddragelse. 4. https://www.regioner.dk/sundhed/kvalitet-og-styring/patientinddragelse

[45] National Institute for Health and Clinical Excellence (2015) Equity and Excellence: Liberating the NHS (White Paper). Stationery Office.

https://www.gov.uk/government/publications/liberating-the-nhs-white-paper

[46] Nuffield Council on Bioethics (2009) Dementia: Ethical Issues. http://nuffieldbioethics.org/project/dementia

[47] Mackenzie, C. and Stoljar, N. (2000) Relational Autonomy: Feminist Perspectives on Autonomy, Agency, and the Social Self. Oxford University Press, Oxford, $314 \mathrm{p}$.

[48] Walter, J.K. and Ross, L.F. (2014) Relational Autonomy: Moving beyond the Limits of Isolated Individualism. Pediatrics, 133, S16-S23. http://www.ncbi.nlm.nih.gov/pubmed/24488536 https://doi.org/10.1542/peds.2013-3608D

[49] Read, S.T., Toye, C. and Wynaden, D. (2017) Experiences and Expectations of Living with Dementia: A Qualitative Study. Collegian, 24, 427-432. https://linkinghub.elsevier.com/retrieve/pii/S1322769616300877 https://doi.org/10.1016/j.colegn.2016.09.003 